\title{
Asymmetric Oxidative Coupling of Phenols and Hydroxycarbazoles
}

Houng Kang, Young Eun Lee, Peddiahgari Vasu Govardhana Reddy, Sangeeta Dey, Scott E. Allen, Kyle A. Niederer, Paul Sung, Kirsten Hewitt, Carilyn Torruellas, Madison R. Herling, and Marisa C. Kozlowski*10

Department of Chemistry, Roy and Diana Vagelos Laboratories, University of Pennsylvania, Philadelphia, Pennsylvania 19104, United States

\section{Supporting Information}

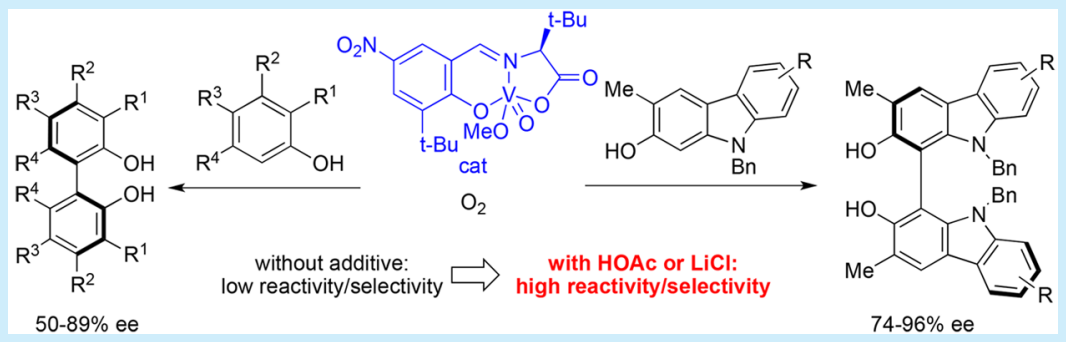

ABSTRACT: The first examples of asymmetric oxidative coupling of simple phenols and 2-hydroxycarbazoles are outlined. Generation of a more vanadium catalyst by ligand design and by addition of an exogenous Brønsted or Lewis acid was found to be key to coupling the more oxidatively resistant phenols. The resultant vanadium complex is both more Lewis acidic and more strongly oxidizing. Good to excellent levels of enantioselectivity could be obtained, and simple trituration readily provided the products with $\geq 95 \%$ ee.

$\mathrm{T}$

he axial chiral biaryl motif is found in many natural products (Scheme 1$)^{1}$ as well as in structures important in catalysis

Scheme 1. Examples of Chiral Biphenols and Binaphthols
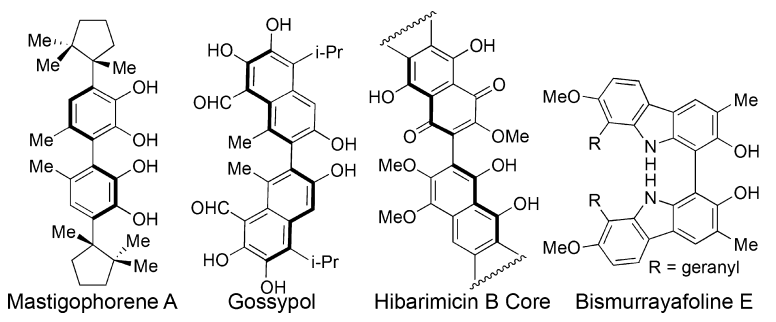

such as $1,1^{\prime}$-binaphthol. ${ }^{2}$ Approaches involving redox-neutral cross-couplings, in particular Suzuki couplings, have been successful for a range of binaphthyl and biphenyl structures with some limitations on structure. ${ }^{3-5}$ Over the past 25 years, oxidative asymmetric catalysis has been successful in generating enantioenriched binaphthol structures by means of $\mathrm{Cu},{ }^{6} \mathrm{Ru},{ }^{7} \mathrm{~V}$, and $\mathrm{Fe}^{9}$ catalysts. The absence of any prefunctionalization at the centers undergoing $\mathrm{C}-\mathrm{C}$ bond formation confers several advantages to this latter approach with respect to overall efficiency.

However, oxidative asymmetric coupling has been noticeably absent with phenols vs 2-naphthols. The phenol substrate type is both more difficult to oxidize and subject to oxidative coupling at a larger number of reactive sites (Scheme 2). The latter feature can be controlled by appropriate substitution and has been addressed with a number of catalytic systems particularly with

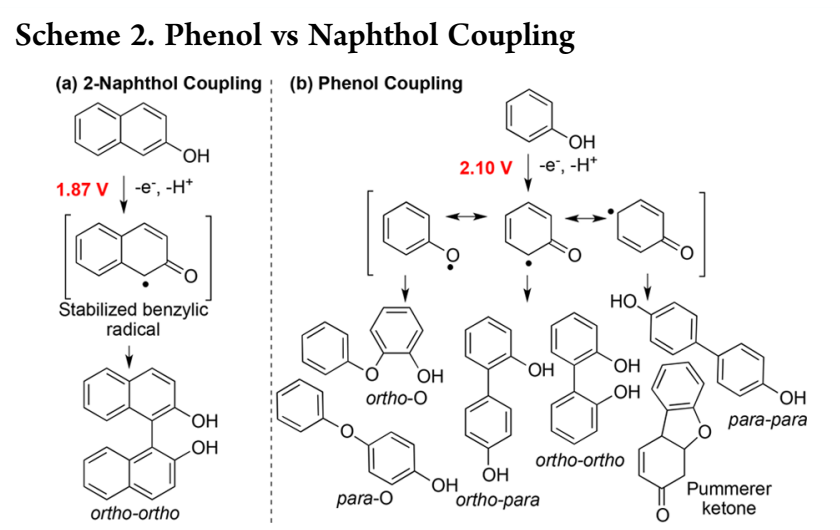

reference to hetero cross-coupling, ${ }^{10}$ but the former issue has proved to be a significant impediment with only one coupling having been reported ( $12 \%$ yield, $13 \%$ ee). ${ }^{11}$ There are no reports of highly enantioselective phenol couplings, although organocatalytic approaches using a preoxidized reaction partner (quinone or iminoquinone) have been successful. ${ }^{12}$

Based on the report of vanadyl(IV) acetoacetonate in phenol coupling, ${ }^{13}$ we were inspired to use vanadium complexes as they appear to have the requisite baseline reactivity to catalytically couple phenols. In addition, the success of chiral vanadium catalysts in the asymmetric coupling of naphthols (Scheme $3 \mathrm{~A})^{8}$ provides support for use of these architectures in the control of

Received: August 17, 2017

Published: October 12, 2017 
Scheme 3. Vanadium Catalysts in Oxidative Coupling

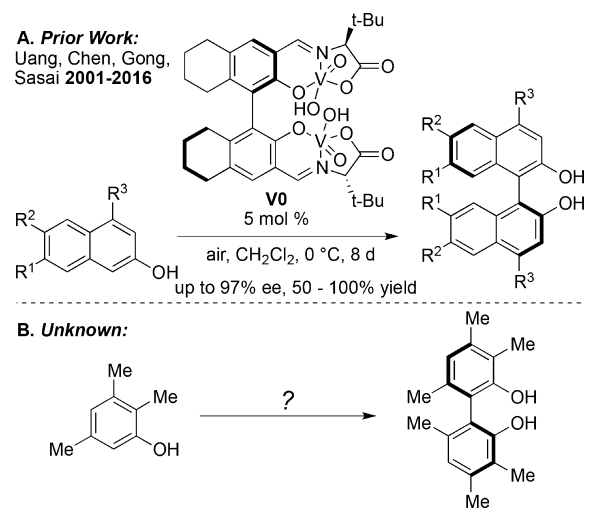

atroposelective couplings. In this report, we describe how vanadium catalysts were engineered to create a more reactive system that also enables control of enantioselectivity in oxidative phenol coupling (Scheme 3B). ${ }^{14}$

Beginning with one of the most promising vanadium catalysts reported in naphthol coupling, V0 (Scheme 3A), ${ }^{8 c, d}$ la was examined (eq 1). Mixtures of two products were observed consisting of ortho-ortho coupled $\mathbf{2}$ a and para-para coupled $3 \mathbf{a}$ (eq 1). Notably, none of the other possibilities (Scheme 2) were observed.



However, the reaction was irreproducible, which was attributed to the exact preparation of the catalyst and its resultant hydration state. ${ }^{8 \mathrm{a}-\mathrm{i}}$ Dried samples were less reactive, presumably due to formation of oxo-bridged species. Ultimately, a much more reproducible protocol was developed using $\mathrm{VO}(\mathrm{OEt})_{3}$ to produce $\mathrm{V} 1 .{ }^{15}$ With this procedure, $37 \%$ ee was observed for $\mathbf{2 a}$ indicating that the catalyst V1 was capable of controlling the enantioselectivity (Figure 1). However, the overall reactivity was still poor with $51 \%$ of starting material 1a remaining after 3 days. In addition, both the ortho-ortho and para-para coupling products were formed at about the same rate (2a:3a 28\%:21\%, Figure 1)

Reasoning that deprotonation of the substrate or additional activation of the catalyst was necessary, a screen of additives was

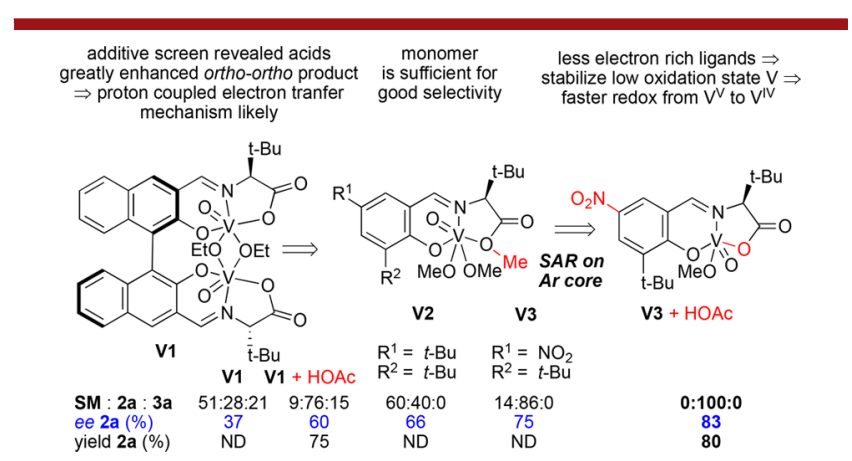

Figure 1. Catalyst evolution in the asymmetric phenol coupling (eq 1). performed. Protic acids (see Supporting Information (SI)) resulted in the greatest improvement in terms of reactivity and selectivity consistent with protonation of the catalyst being involved. Notably, bases (e.g., $\mathrm{Et}_{3} \mathrm{~N}$ ) resulted in a complete loss of reactivity. Examining concentration, equivalents of acid, and solvent revealed that $0.5 \mathrm{M}$ in $\mathrm{CH}_{2} \mathrm{Cl}_{2}$ or 1,2-dichloroethane (DCE) with 6.25 equiv of $\mathrm{HOAc}$ was optimal with $\mathrm{V} 1$ producing $75 \%$ of $2 \mathrm{a}$ in $60 \%$ ee (Figure 1 ).

To further improve selectivity, modifications of the catalyst framework were investigated. Changing the amino acid substituent did not offer any advantage. Examination of various dimeric vanadium catalysts with different biaryls and different linkers resulted in no improvement. Reasoning that a large group may be all that is needed in the position formerly occupied by the chiral axis to confer selectivity, a monomeric catalyst with a tertbutyl substituent at the $\mathrm{R}^{2}$ position was employed (V2) and an improvement in selectivity was seen ( $66 \%$ ee). A study of various $\mathrm{R}^{1}$ and $\mathrm{R}^{2}$ groups of the monomer found that a more Lewis acidic, and hence more strongly oxidizing catalyst (V3), led to both higher reactivity and higher selectivity (86:0 ortho-ortho/ para-para, $75 \%$ ee). When combined with the HOAc additive, full conversion to only the ortho-ortho adduct was observed and the enantioselectivity improved to $83 \%$ ee.

Examination of a range of phenols (Scheme 4) showed that a methyl group ortho to the phenol was required with groups that

Scheme 4. Scope of Phenol Coupling ${ }^{a}$

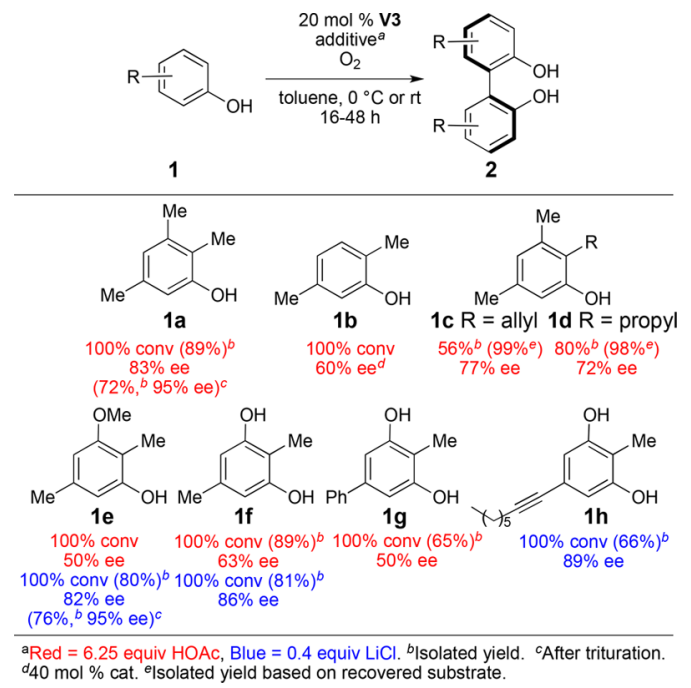

were smaller $(\mathrm{H})$ or larger $(t-\mathrm{Bu})$ leading to very low or no selectivity. However, other substrates with an ortho-methyl (1) ortho-allyl (1c), or ortho-propyl group (1d) gave similar selectivities. Notably, one trituration was found to increase the enantiomeric excess of the filtrate to $\geq 95 \%$ ee. More electronrich dioxygenated substrates $\mathbf{1 e}-\mathbf{1 h}$ reacted quickly even at $0{ }^{\circ} \mathrm{C}$. Screening of additional additives (see SI) revealed that the Lewis acid $\mathrm{LiCl}$ afforded higher selectivies for $\mathbf{1 e}, \mathbf{1 f}$, and $\mathbf{1 h}$.

It has been theorized that natural products such as bismurrayafoline $\mathrm{E}$ (Scheme 1) are synthesized biosynthetically by oxidative coupling. ${ }^{16}$ With vanadium catalyst V3, the parent system $\left(4 a, R^{1}=\mathrm{Me}, \mathrm{R}^{2}=\mathrm{H}, \mathrm{NR}^{3}=\mathrm{NH}\right)$ underwent unselective oxidation, likely due to reaction of the amine. Addition of an $\mathrm{N}$ benzyl substituent gave rise to a rapid, chemoselective oxidative coupling with V3 (70\% ee). Optimization of the vanadium substituent (see SI) revealed that V4, the isopropoxy analog of 
V3, was optimal (Scheme 5, 91\% yield, $87 \%$ ee). For the Nsubstituent, smaller (Me, $71 \%$ ee) or larger $(i-\operatorname{Pr}, 42 \%$ ee; $2,4,6$ trimethylbenzyl, $37 \%$ ee) groups were deleterious.

Scheme 5. Scope of 2-Hydroxycarbazole Coupling (eq 2) ${ }^{a}$
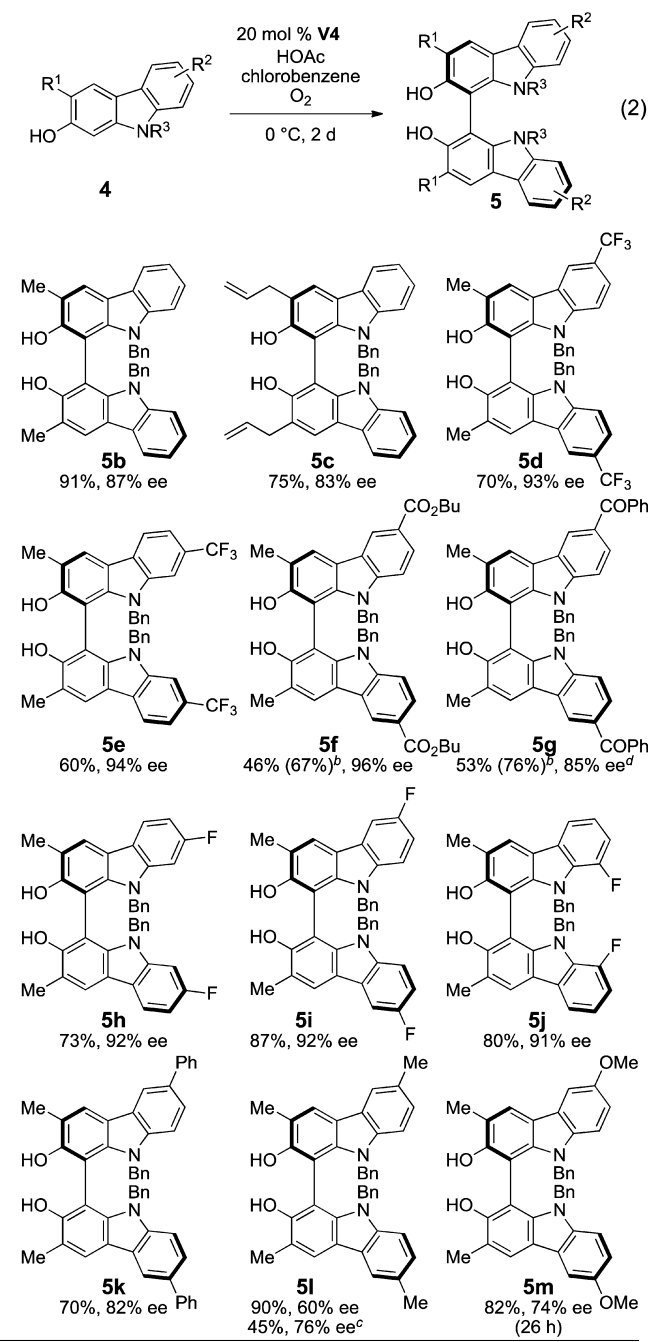

${ }^{a}$ Reaction conditions: $20 \mathrm{~mol} \% \mathrm{V4}, 6.5$ equiv of $\mathrm{AcOH}, \mathrm{O}_{2}, 0.5 \mathrm{M}$ chlorobenzene $0{ }^{\circ} \mathrm{C}, 48 \mathrm{~h} .{ }^{b}$ Based on recovered starting material. ${ }^{c}$ Reaction was conducted at $-15{ }^{\circ} \mathrm{C} .{ }^{d} \mathrm{HFIP} / \mathrm{PhCl}$ as a solvent.

Scheme 5 outlines the scope of the asymmetric oxidative couplings of $\mathrm{N}$-benzylated-2-hydroxycarbazoles. With an allyl group adjacent to the phenol, good enantioselectivity was observed (5c). Electron-withdrawing groups on the distal ring result in improvements in selectivity (5d-5k, 82-96\% ee) with good levels of conversion (67-87\% yield). Electron-donating groups such as methyl or methoxy result in good reactivity with moderate selectivity $(\mathbf{5 1}, \mathbf{5 m})$.

Control experiments with radical inhibitor TEMPO resulted in a dramatic reduction in conversion (Table 1 , entry 1 vs 2 ). In the absence of $\mathrm{O}_{2}, 9 \%$ and $26 \%$ conversions were observed with 20 and $50 \mathrm{~mol} \%$ catalyst, respectively. This result indicates that each vanadium abstracts one electron as would be the case with a vanadium(V) to vanadium(IV) redox event.

A possible mechanism consistent with these results is outlined in Figure 2. Water and other protic additives, which were found to be advantageous, are proposed to prevent aggregation of the vanadium complexes to forms that were less susceptible to ligand
Table 1. Control Experiments in Asymmetric Coupling ${ }^{a}$

\begin{tabular}{cll} 
entry & \multicolumn{1}{c}{ condition } & conversion (\%) \\
1 & control & 10 \\
2 & 0.2 equiv of TEMPO & 3 \\
3 & $\mathrm{~N}_{2}$ atmosphere & $9(3$ days $)$ \\
4 & $50 \mathrm{~mol} \% \mathrm{~V} 3, \mathrm{~N}_{2}$ atmosphere & $26(3$ days $)$
\end{tabular}

${ }^{a}$ Reaction of $1 \mathrm{a}$ with $20 \mathrm{~mol} \% \mathrm{~V} 3,6.25$ equiv $\mathrm{HOAc}, \mathrm{O}_{2}, \mathrm{PhMe}, \mathrm{rt}, 2$ d.

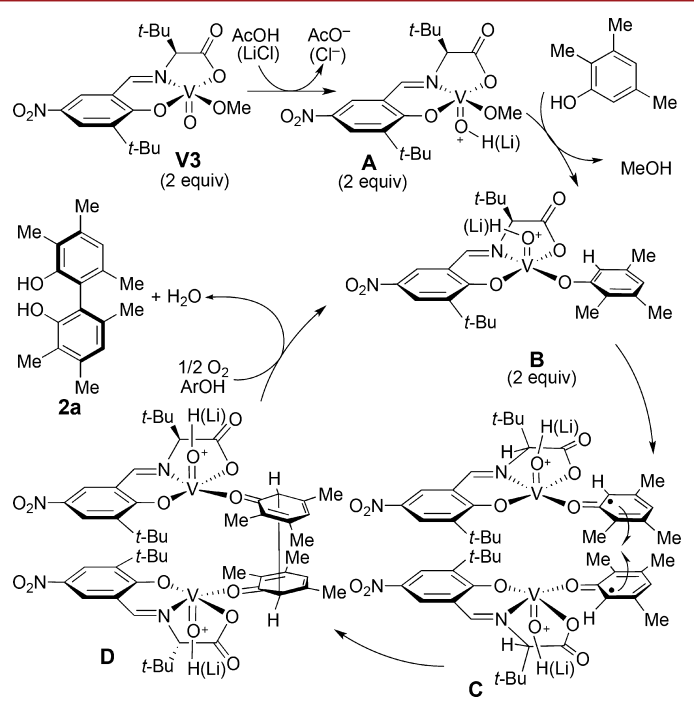

Figure 2. Proposed mechanism.

exchange, and hence reaction, with the phenols. However, the greatly improved results with acetic acid were puzzling since naphthol or phenol deprotonation to effect ligation is often suggested as a first step. In the presence of an excess of acid (6.25 equiv) relative to substrate, such a step seems unlikely under these conditions. Thus, we propose an additional accelerating effect of the acetic acid additive (or the $\mathrm{LiCl}$ additive) involving activation of the vanadium complex. Namely protonation of the vanadium oxy group (or coordination of $\mathrm{Li}^{+}$in the case of $\mathrm{LiCl}$ ) generates a more Lewis acidic species A (Figure 2). The protonated version of $\mathbf{A}$ was observed by mass spectrometry, and calculations indicate a favorable association of $\mathbf{V} \mathbf{3}$ with acetic acid (see SI). Subsequent associative exchange with phenol would form adduct $\mathbf{B}$, which was also observed by mass spectrometry. Protonation also enhances the oxidizing ability of the vanadium(V) species. Redox transfer to generate a vanadium(IV) keto radical $\mathbf{C}$ would account for the radical inhibitor results seen. Coupling via an intermolecular process or, if vanadium aggregates are formed, via an intramolecular process gives rise to $\mathbf{D}$, consistent with the nonlinear effects (see SI). Release and tautomerization lead to product $2 \mathrm{a}$.

$\mathrm{X}$-ray crystallographic analysis of $\mathbf{2} \mathbf{a}$ indicated the $(S)$ absolute axial configuration was present (eq 3). Circular dichroism

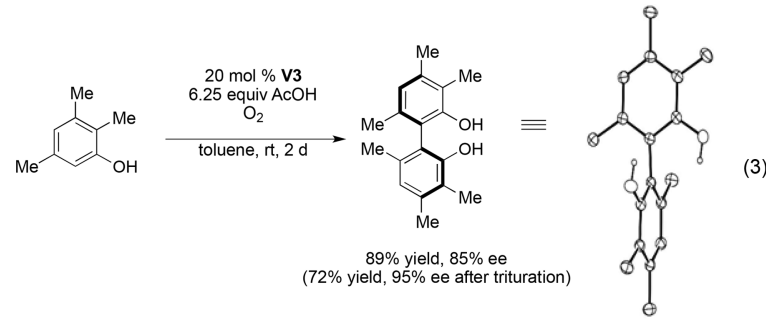


measurements (see SI) support the same $(S)$ axial for the bishydroxycarbazoles. On this basis, a preliminary stereochemical model can be proposed as illustrated in intermediate C of Figure 2. The phenol coordinates to minimize steric interactions; namely, the less hindered lone pair of the phenol coordinates to the vanadium and the less substituted orthoposition orients closest to the catalyst, placing the larger orthosubstituent into unoccupied space. Approach of the second phenol from the face opposite the tert-butyl group then gives rise to the observed stereochemistry.

In summary, we report the first enantioselective oxidative coupling of phenols and 2-hydroxycarbazoles to give rise to adducts not available with alternate approaches. ${ }^{3-5,12}$ A much more active vanadium oxidative catalyst was developed capable of acting on these less reactive substrates to form the axial chiral dimers efficiently. Less electron-rich ligands were employed which stabilize the low valent vanadium(IV) and destabilize the high valent vanadium $(\mathrm{V})$ giving rise to a more potent oxidizing species. Counterintuitively, the addition of a Brønsted or Lewis acid was found to accelerate the process, indicating that ligand exchange of the substrate is not driven by deprotonation of the phenol. Rather, the Brønsted acid likely activates the vanadium catalyst enhancing both its oxidizing properties and its ability to coordinate a neutral phenol. Together, these features should prove useful in the design of other asymmetric oxidants.

\section{ASSOCIATED CONTENT}

\section{S Supporting Information}

The Supporting Information is available free of charge on the ACS Publications website at DOI: 10.1021/acs.orglett.7b02552.

Experimental procedures for all experiments and characterization data (PDF)

Crystallographic data for 2a (CIF)

\section{AUTHOR INFORMATION}

\section{Corresponding Author}

*E-mail: marisa@sas.upenn.edu.

\section{ORCID $\odot$}

Marisa C. Kozlowski: 0000-0002-4225-7125

Notes

The authors declare no competing financial interest.

\section{ACKNOWLEDGMENTS}

We are grateful to the NIH (GM-112684) and the NSF (CHE1464778) for financial support of this research. Partial instrumentation support was provided by the NIH and NSF (1S10RR023444, 1S10RR022442, CHE 0840438, CHE0848460, 1S10OD011980). P.V.G.R. acknowledges the Raman Fellowship for financial support [F.No.5.102/2016(1c)]. Drs. Rakesh Kohli and Charles W. Ross III (UPenn) are acknowledged for obtaining HRMS data. We thank Virgil Percec and Benjamin Partridge (UPenn) for assistance with CD measurements.

\section{REFERENCES}

(1) (a) Fukuyama, Y.; Asakawa, Y. J. Chem. Soc., Perkin Trans. 1 1991, 2737. (b) Kenar, J. A. J. Am. Oil Chem. Soc. 2006, 83, 269. (c) Narayan, S.; Roush, W. R. Org. Lett. 2004, 6, 3789. (d) Nutan, M. T. H.; Hasan, C. M.; Rashid, M. A. Fitoterapia 1999, 70, 130.
(2) For a review on asymmetric biaryl formation: Bringmann, G.; Price Mortimer, A. J.; Keller, P. A.; Gresser, M. J.; Garner, J.; Breuning, M. Angew. Chem., Int. Ed. 2005, 44, 5384.

(3) (a) Cammidge, A. N.; Crépy, K. V. L Chem. Commun. 2000, No. 18, 1723. (b) Cammidge, A. N.; Crepy, K. V. J. Org. Chem. 2003, 68, 6832.

(4) (a) Yin, J.; Buchwald, S. L. J. Am. Chem. Soc. 2000, 122, 12051. (b) Shen, X.; Jones, G. O.; Watson, D. A.; Bhayana, B.; Buchwald, S. L. J. Am. Chem. Soc. 2010, 132, 11278.

(5) (a) Tang, W.; Patel, N. D.; Xu, G.; Xu, X.; Savoie, J.; Ma, S.; Hao, M. H.; Keshipeddy, S.; Capacci, A. G.; Wei, X.; Zhang, Y.; Gao, J. J.; Li, W.; Rodriguez, S.; Lu, B. Z.; Yee, N. K.; Senanayake, C. H. Org. Lett. 2012, 14, 2258. (b) Xu, G.; Fu, W.; Liu, G.; Senanayake, C. H.; Tang, W. J. Am. Chem. Soc. 2014, 136, 570.

(6) (a) Nakajima, M.; Kanayama, K.; Miyoshi, I.; Hashimoto, S.-i. Tetrahedron Lett. 1995, 36, 9519. (b) Nakajima, M. M. I.; Kanayama, K.; Hashimoto, S.-i.; Noji, M.; Koga, K. J. Org. Chem. 1999, 64, 2264. (c) Li, X.; Yang, J.; Kozlowski, M. C. Org. Lett. 2001, 3, 1137. (d) Li, X.; Hewgley, J. B.; Mulrooney, C. A.; Yang, J.; Kozlowski, M. C. J. Org. Chem. 2003, 68, 5500.

(7) Irie, R.; Masutani, K.; Katsuki, T. Synlett 2000, 1433.

(8) (a) Chu, C.-Y.; Hwang, D.-R.; Wang, S.-K.; Uang, B.-J. Chem. Commun. 2001, 980. (b) Hon, S.-W.; Li, C.-H.; Kuo, J.-H.; Barhate, N. B.; Liu, Y.-H.; Wang, Y.; Chen, C.-T. Org. Lett. 2001, 3, 869. (c) Luo, Z.; Liu, Q.; Gong, L.; Cui, X.; Mi, A.; Jiang, Y. Chem. Commun. 2002, 914. (d) Somei, H.; Asano, Y.; Yoshida, T.; Takizawa, S.; Yamataka, H.; Sasai, H. Tetrahedron Lett. 2004, 45, 1841. (e) Guo, Q.-X.; Wu, Z.-J.; Luo, Z.B.; Liu, Q.-Z.; Ye, J.-L.; Luo, S.-W.; Cun, L.-F.; Gong, L.-Z. J. Am. Chem. Soc. 2007, 129, 13927. (f) Takizawa, S.; Katayama, T.; Kameyama, C.; Onitsuka, K.; Suzuki, T.; Yanagida, T.; Kawai, T.; Sasai, H. Chem. Commun. 2008, 1810. (g) Takizawa, S.; Katayama, T.; Sasai, H. Chem. Commun. 2008, 4113. (h) Takizawa, S.; Kodera, J.; Yoshida, Y.; Sako, M.; Breukers, S.; Enders, D.; Sasai, H. Tetrahedron 2014, 70, 1786. (i) Sako, M.; Takeuchi, Y.; Tsujihara, T.; Kodera, J.; Kawano, T.; Takizawa, S.; Sasai, H. J. Am. Chem. Soc. 2016, 138, 11481.

(9) (a) Egami, H.; Katsuki, T. J. Am. Chem. Soc. 2009, 131, 6082. (b) Egami, H.; Matsumoto, K.; Oguma, T.; Kunisu, T.; Katsuki, T. J. Am. Chem. Soc. 2010, 132, 13633. (c) Oguma, T.; Katsuki, T. J. Am. Chem. Soc. 2012, 134, 20017. (d) Matsumoto, K.; Egami, H.; Oguma, T.; Katsuki, T. Chem. Commun. 2012, 48, 5823. (e) Narute, S.; Parnes, R; Toste, F. D.; Pappo, D. J. Am. Chem. Soc. 2016, 138, 16553.

(10) (a) Elsler, B.; Schollmeyer, D.; Dyballa, K. M.; Franke, R.; Waldvogel, S. R. Angew. Chem., Int. Ed. 2014, 53, 5210. (b) Lee, Y. E.; Cao, T.; Torruellas, C.; Kozlowski, M. C. J. Am. Chem. Soc. 2014, 136, 6782. (c) Libman, A.; Shalit, H.; Vainer, Y.; Narute, S.; Kozuch, S.; Pappo, D. J. Am. Chem. Soc. 2015, 137, 11453. (d) More, N. Y.; Jeganmohan, M. Org. Lett. 2015, 17, 3042. (e) Huang, Z.; Lumb, J. P. Angew. Chem., Int. Ed. 2016, 55, 11543.

(11) Takizawa, S.; Katayama, T.; Somei, H.; Asano, Y.; Yoshida, T.; Kameyama, C.; Rajesh, D.; Onitsuka, K.; Suzuki, T.; Mikami, M.; Yamataka, H.; Jayaprakash, D.; Sasai, H. Tetrahedron 2008, 64, 3361.

(12) (a) Chen, Y.-H.; Cheng, D.-J.; Zhang, J.; Wang, Y.; Liu, X.-Y.; Tan, B. J. Am. Chem. Soc. 2015, 137, 15062. (b) Wang, J.-Z.; Zhou, J.; Xu, C.; Sun, H.; Kürti, L.; Xu, Q.-L. J. Am. Chem. Soc. 2016, 138, 5202.

(13) Hwang, D. R.; Chen, C. P.; Uang, B. J. Chem. Commun. 1999, 1207.

(14) Parts of this work are described in: (a) Allen, S. E., Studies Toward the Asymmetric Oxidative Coupling of Phenols. PhD, Univ. Pennsylvania, 2013. (b) Lee, Y. E. Selective Oxidative Homo and Cross Coupling of Phenols. PhD, Univ. Pennsylvania, 2016.

(15) Hartung, J.; Drees, S.; Greb, M.; Schmidt, P.; Svoboda, I.; Fuess, H.; Murso, A.; Stalke, D. Eur. J. Org. Chem. 2003, 2003, 2388.

(16) Racemic coupling of 4a has been reported with para-chloroanil in modest yield (38\%): Knölker, H.-J.; Goesmann, H.; Hofmann, C. Synlett 1996, 1996, 737. 